\title{
Arthur Azevedo e a teatralidade circense
}

\author{
Erminia Silva
}

m 20 de agosto de 1893, uma nota no jornal $O$ Paiz (RJ) mexeu com a imprensa carioca: "O teatro S. Pedro de Alcântara [atual João Caetano], depois que acabar a série de récitas da companhia do D. Maria II, transformar-se-á em circo". A nota acrescentava que a direção seria do clown Frank Brown.

Devido à Revolta da Armada, que só se encerraria em março de 1894, aquela estréia anunciada não ocorreu. Com o fim da Revolta, a Empresa Emílio Fenandes \& Co., companhia eqüestre, estreou naquele Teatro em 27 de abril. Em letras garrafais, informava que o São Pedro seria transformado, pela primeira vez, em circo, destacando a atriz/eqüestre Rosita de La Plata.

Não era a primeira vez que Frank Brown vinha ao Brasil, e nem que se apresentava em um teatro. Em 1876, junto com a família argentina dos Podestá, havia se instalado no então Teatro Imperial D. Pedro II (Gazeta de Notícias, 13.06.1876). Entretanto, a novidade era a de se apresentar no Teatro São Pedro e transformá-lo em circo.

A primeira menção à estréia foi de Arthur Azevedo, que, apesar de não tê-la assistido, escreveu em sua coluna Palestra, na primeira página do jornal:
A cidade reanima-se. A pouco e pouco vai se desvanecendo a sinistra lembrança dos bombardeios e tiroteios que ainda há dois meses nos sobressaltavam.

Espero que a companhia eqüestre do S. Pedro de Alcântara venha consolar definitivamente o Zé-povinho, que é doido por peloticas, e dá mais apreço a Rosita de La Plata que à própria Sarah Bernhardt. Entretanto, para os espíritos mais refinados aí está o Mancinelli, com uma companhia lírica de primeira ordem (O Paiz, 28.04.1894).

O modo de denominar espetáculos circenses por "peloticas" era comum no período. Arthur Azevedo utilizava o termo em seus textos, principalmente quando queria passar uma idéia desqualificadora do circo e do gosto do público. Ao mesmo tempo em que era um dos mais importantes literatos e intelectuais dos anos 1880/90 - autor de obras teatrais do gênero ligeiro, como operetas, paródias e, principalmente, revistas - Arthur foi também um crítico contumaz daqueles gêneros e o principal articulador da luta pela construção do "Teatro Nacional”, o que era visto por seus críticos como contradição (cf. Mencarelli, 1999, p. 64).

Erminia Silva é pesquisadora. Este artigo faz parte da tese de doutorado, As múltiplas linguagens na teatralidade circense. Benjamim de Oliveira e o circo-teatro no Brasil do século XIX a início do XX. Campinas: Unicamp, 2003. 
Não era privilégio dos circenses e de seu público receber críticas desfavoráveis daquele autor; que, aliás, apenas para acrescentar mais uma contradição, era freqüentador assíduo dos circos.

Seu texto explicita a preferência do público pelo circo, em detrimento do que considerava um teatro sério. Para Mencarelli, a "compreensão do que se passava nos teatros com relação à freqüência do público" era um dos temas que ocupavam constantemente Arthur Azevedo, mas tentar procurar uma "clareza de suas posições com relação ao tema não é tarefa fácil”. Embora em alguns momentos ele questione claramente as escolhas do público, em outros é categórico em afirmar que o público sabia reconhecer o que era bom; o problema estaria na qualidade da literatura teatral produzida, e não no gênero. Entretanto, quando um espetáculo era a própria representação da indesejada tradição do teatro de feira, competindo com o teatro que desejava, não era condescendente com o gosto do público.

Arthur Azevedo, na verdade, do meu ponto de vista, percebia como um problema o fato dos espetáculos circenses disputarem o mesmo público que ia aos teatros. A hipótese proposta é que a heterogeneidade do público circense era reflexo da heterogeneidade da população que freqüentava os espaços urbanos de entretenimento.

Mas, antes de continuarmos com a questão do tipo de espetáculo, de lugar e de público que o assistia, é interessante saber por quê Arthur Azevedo fez a comparação entre Rosita de La Plata e Sarah Bernhardt. Façamos uma retrospectiva.

Em junho de 1893, antes da Revolta da Armada, estreava no Campo de São Cristóvão, Rio de Janeiro, o Circo Universal de Albano Pereira, com 22 artistas, anunciando "piramidais" pantomimas ornadas de música, marchas e bailados. Alguns dias depois, os jornais noticiavam, freneticamente, a vinda de Sarah Bernhardt, que apresentaria dez récitas, em francês, no Teatro Lírico (O Paiz, 11 e 13.06.1893).
Aí a temos de novo, a grande Sarah, a grande intérprete do sofrimento humano, a artista genial em cujos nervos divinos vibra, estorcese, soluça e esplende a alma de todas as raças, bárbaras ou cultas, vingativa ou amante, piedosa ou cruel, com uma verdade e um brilho que a ela se pode perguntar, num assombro, como outrora se perguntou a Menandro: "Oh Sarah, Oh Vida, qual de vós imita a outra?" (O Paiz, 15.06.1893; a crônica foi assinada por Eduardo Salamonde).

Os assuntos dos jornais à época eram dois: os conflitos políticos e Sarah Bernhardt. Albano Pereira, em meio àquele volume de noticiários da grande atriz, colocou algumas linhas no jornal: "Parabéns aos moradores de S. Cristóvão [que] para passarem uma noite divertidíssima não precisam ir ver a Sarah: é ir ao grande Circo Universal, dirigido pelo artista Albano Pereira" (O Paiz, 24.06.1893).

Apesar de seu anúncio fazer referência apenas aos moradores de São Cristóvão, convidando-os a não irem ao centro da cidade, pois no próprio bairro teriam divertimento garantido, escrevia também a uma população de vários bairros vizinhos, que utilizava bondes. Era comum, nas propagandas de circos e teatros do período, anunciar-se que depois do espetáculo haveria bondes para todas as linhas, o que permitia acesso às opções de lazer, em vários horários, em particular o noturno, a um número cada vez maior e mais heterogêneo da população, não só dos bairros vizinhos como, também, do centro da cidade. São Cristóvão foi, desde o início, privilegiado pela instalação de redes de transportes. $\mathrm{O}$ bonde que ligava o centro aos bairros passava exatamente na frente de onde o circo estava armado.

Utilizando-se de um jornal diário, que era lido não só por uma parcela "culta" da população, Pereira se dirigia ao conjunto de leitores, mas visava àqueles que compunham o público do circo. O circo competia diretamente com o Lírico, "teatro por excelência das elites cariocas", 
que Arthur indicava aos "espíritos mais refinados", localizado privilegiadamente no centro da cidade, no Largo da Carioca, mas do qual nem de longe se mencionava que havia sido construído, inicialmente, com a dupla finalidade de servir de teatro e de circo, e que, antes mesmo de ser o Imperial Teatro D. Pedro II, era popularmente conhecido como Circo da Guarda Velha (cf. Coaracy, 1965, p. 140; Souza, 2002, p. 245).

Mas o que, afinal, Albano Pereira oferecia ao Zé-povinho, e aos espíritos menos refinados, que era preferível a Sarah?

Além dos artistas em acrobacias de solo e aérea, e dos animais, havia um grande repertório de pantomimas. No dia em que Pereira mandava o seu recado aos moradores do bairro, o circo anunciava em suas propagandas-cartazes "grandiosas pantomimas de grande movimento, ornadas de música e bailados". Uma dessas pantomimas, $O$ remorso vivo, traduzida por Furtado Coelho e com música de Artur Napoleão, além da participação de todos os artistas da companhia, chamava a atenção do público. A peça tinha sido representada pela primeira vez no Teatro Ginásio do Rio de Janeiro, em 1866, e, definida na ocasião como um "drama-fantástico-lírico", tornou-se um grande sucesso de público. A bibliografia corrente somente menciona suas montagens por companhias teatrais. Entretanto, as fontes levantadas para esse estudo revelam que, desde 1881 até pelo menos 1910, diversos grupos circenses a encenaram. Naquele ano de 1893, Albano Pereira não descreveu a montagem, mas o fez seis anos depois, o que nos permite entrar em contato, por um lado, com a livre interpretação que os circenses faziam dos textos literários ou dramatúrgicos, parodiando-os e ajustando-os ao picadeiro; por outro lado, com o que se pressupóe fosse o gosto do público.

Naquela montagem, o título da pantomima foi $O$ casamento do Arlequim ou $O$ remorso vivo, lançando mão do velho arsenal das arlequinadas e misturando-o ao enredo de um me- lodrama. Essa mistura estaria de acordo com a definição que Arnold Hauser faz do melodrama, na qual a pantomima seria um dos seus protótipos mais importantes $(1998,701)$, com seu caráter espetacular, apelo aos sentimentos, elementos da dança e musicais variados. Conforme propaganda do jornal, ter-se-ia, após a exibição de "exercícios de alta equitação, ginásticos, acrobáticos", a apresentação da "importantíssima pantomima fantástica”:

Dividida em oito quadros. Marchas, bailados, transformaçóes etc., na qual toma parte toda companhia e o esplêndido corpo de baile.

Personagens: Paschoal, velho camponês, Sr. Fructuoso; Arlequim, cozinheiro de Paschoal, amante da Columbina, Sr.Luiz Pereira; Pierrot, filho de Paschoal, Sr.A. Freitas; D. Phelippi, pretendente à mão de Columbina, Sr. Albano Pereira; Columbina Filha de Paschoal e amante do Arlequim, D. Perez; O embaixador, Sr. A. Pereira; O Esqueleto, Sr. L. Pereira. Camponeses, camponesas, povo etc.

Números de Música: $1^{\circ}$ Ouverture $2^{\circ}$ Grande valsa $-3^{\circ}$ Marcha dos embaixadores $-4^{\circ}$ Bailado das ninfas $-5^{\circ}$ Pandeiretta - $6^{\circ}$ Bailado de D. Fellipe - $7^{\circ}$ Marcha fúnebre $-8^{\circ}$ Acorde $-9^{\circ}$ Valsa - $10^{\circ}$ Galope $11^{\circ}$ Acorde $-12^{\circ}$ Valsa $-13^{\circ}$ Marcha fúnebre $-4^{\circ}$ Valsa.

Denominação dos quadros: $1^{\circ} \mathrm{O}$ sono do amor. $2^{\circ} \mathrm{A}$ despedida do Arlequim. $3^{\circ} \mathrm{A}$ embaixada. $4^{\circ}$ Grande bailado. $5^{\circ} \mathrm{O}$ assassinato. $6^{\circ} \mathrm{O}$ remorso. $7^{\circ}$ Casamento de Arlequim. $8^{\circ}$ Deslumbrante apoteose final.

Mise-en-scène do artista Albano Pereira (Diário de Campinas, 22.08.1899).

$\mathrm{Na}$ programação do Lírico, no mesmo mês de junho de 1893, Sarah estreava com o drama em quatro atos $A$ Tosca, seguida de vários "clássicos" do teatro, todos representados em francês. Em sua crítica teatral, Chrispiniano da Fonseca informa que o teatro não lotou, mas 
que o público que compareceu era aquele "típico" do Lírico, ou seja, formado pela "melhor sociedade do Rio de Janeiro" (O Paiz, 17.06.1893). Apesar dessa conclusão, que tentava aliviar os problemas e realçar a atriz, não parece que a "boa sociedade" chegou a ocupar todos os espaços do teatro. A questão do preço poderia ter sido, para a época, um obstáculo. Porém, mesmo que fosse cobrado um preço maior para as apresentações de Sarah no Lírico, a elite da cidade do Rio de Janeiro, na época, para quem isso não seria um problema, era suficiente para lotar o teatro, o que não aconteceu.

Durante o período em que Sarah e o Circo Universal estiveram no Rio de Janeiro, outras companhias teatrais, que se exibiam nos teatros do centro da cidade, competiam com as apresentaçóes da atriz com peças de "grande espetáculo": óperas burlescas; dramas marítimos; comédias; mágicas que prometiam "noite feérica" com "luz elétrica, banda de música, bandeiras, flores"; operetas e revistas; todas anunciadas em O Paiz de maio de 1893. Eram montagens de adaptaçóes melodramáticas, dramalhōes "espetaculosos", como se chamavam na época. Isto, muito provavelmente, deixava Albano Pereira tranqüilo quando mandava recados aos moradores do centro e do bairro para assistirem suas pantomimas. Ele proclamava em seus cartazes o quanto as suas funções eram organizadas com uma "programação chic" (O Paiz, 18.06.1893), e afirmava que elas agradariam mais que a "trágica atriz". Um ano depois, em 1894 quando estreou Frank Brown no São Pedro, apesar de toda a produção em torno das apresentações no Lírico, Arthur Azevedo mencionou que o público tinha preferido peloticas a Sarah.

Se na hierarquia de valorização do que era de fato teatro ou arte teatral, os gêneros ligeiros eram desvalorizados, o conjunto que representava a teatralidade circense não chegava nem a ser considerado como representação teatral ou portando qualquer tipo de teatralidade. A pantomima, por exemplo - vista como uma exibição que "apenas divertia", e que não "cumpria um papel civilizador como o teatro" - era enquadrada em tudo o que era marginalizado, pois misturava mímica, paródias, canto, danças, saltos, mágicas, músicas clássicas com os provocantes e luxuriantes ritmos locais (lundus, maxixes, cançonetas). Os textos que os circenses representavam eram produtos da transmissão oral, e anônimos, frutos de adaptações de obras literárias ou dramáticas (incluindo os musicais). Eram montagens de difícil controle pelas autoridades competentes da censura ou mesmo pelos letrados.

Aqueles artistas, apesar de seguirem um enredo, acabavam por "reescrevê-lo" no palco/ picadeiro com uma produção em "ato" que incorporava os temas contemporâneos e os costumes locais, mesmo no caso de adaptações de textos como A flauta mágica, $O$ remorso vivo, ou Cendrillon. Essa forma de representação e improvisação, além de possibilitar uma maior proximidade entre artista e público, transformavao em co-autor do texto ou enredo, o que era um problema para os que pretendiam que o teatro fosse o texto, a representação e uma função.

Além do mais, os artistas circenses dificilmente eram considerados atores, pois sua prática diferia dos critérios de apreciação daquilo que se supunha ou se idealizava como uma boa representação. Esta visava "definir o bom ator em função da sua capacidade de ser esse ou aquele personagem" e de expressar claramente o seu texto (cf. Roubine, 1998, p. 48). Atores e atrizes considerados "monstros sagrados", como era o caso de Sarah Bernhardt, tinham o seu valor pela capacidade de encarnar um personagem e por sua perfeita dicção.

Rozita de La Plata, assim como várias outras atrizes circenses do período, era a encarnação da própria multiplicidade. Portenha de nascimento, aos dez anos incorporou-se a um circo, aprendendo acrobacia, trapézio, dança e equitação. Em Londres, foi contratada por Frank Brown para uma tournée em Buenos Aires. No circo dos Podestá, junto com Antonio Podestá, foi contratada pelo circo norte-americano Bárnum e Bailey para uma outra tournée pelos 
Estados Unidos e Europa (cf. Castagnino, 1969, p. 131-3; Seibel, 1993, p. 50). Thétard cita Rozita disputando espaço e público com as principais artistas de Paris no final do século XIX. No Brasil, com Frank Brown, realizou várias outras tournées até 1907.

Não só para Arthur Azevedo, mas para muitos cronistas que faziam as críticas teatrais nos jornais, havia um outro problema, talvez tão sério quanto a preferência do público pelo circo. Tratava-se da ocupação do Teatro São Pedro por uma companhia circense. Após a estréia de Frank Brown ali, o Paiz teve que, pela primeira vez, fazer a crônica de um espetáculo circense. $\mathrm{O}$ crítico, que não se identificou, iniciou seu texto dizendo que "um circo improvisado tomou parte do palco e todo o espaço outrora reservado à orquestra”. Essa forma de ocupação mostrou-se inadequada, mas depois de pedidos de desculpas os diretores remediaram os problemas para o próximo espetáculo. Além desses problemas, o crítico afirmou que o programa era fraco, sendo os melhores números os de Rozita, aplaudida "freneticamente", e de Mr. Casthor, que tinha habilidade para imitar tipos de personagens célebres. No final do texto, concluiu:

A companhia, se lhe tirarmos quatro artistas, tem ares de ter vindo da roça. Não valia a pena por tão pouco transformar em circo o teatro de tão gloriosas tradiçôes artísticas (O Paiz, 29.04.1894; grifo meu).

Sem questionar a opinião do cronista, atento para uma pergunta que estava nas entrelinhas da crítica: como se permitiu que aquela imponente construção arquitetônica da Praça Tiradentes, referência teatral da capital federal, de "tão gloriosas tradições artísticas", um "símbolo do teatro erudito" brasileiro, fosse transformado em circo?

No mesmo dia daquela crônica, Arthur Azevedo, sob o pseudônimo de Gavroche (título da revista que escreveu em 1898), redigiu versos na primeira página do jornal $O$ Paiz, não sobre o espetáculo, pois ainda não o havia assistido, mas sobre o comportamento do público.
No S. Pedro
Tal vozeria
Me ensurdecia
Que parecia
Que aquela gente indômita e bravia
Não assistia
A estréia de uma eqüestre companhia
Mas alguma comédia via e ouvia! (O Paiz,
29.04.1894).

As reações do cronista e de Arthur, quanto à ocupação daquele teatro por um circo, falam não só do gosto do público, mas do modo como este ocupa aquele espaço e do seu comportamento. Parte da bibliografia recente sobre a história do teatro (Duarte, 1995; Mencarelli, 1999; Souza, 2002) tem analisado as tensões e debates a propósito do modelo de comportamento que se desejava do público num espaço teatral idealizado, de preferência do tipo italiano, assistindo "civilizadamente" às peças, que lhe proporcionavam regras de comportamento social. Afinal, desejava-se para palcos civilizados platéias civilizadas. Entretanto, dificilmente ocorria nos teatros um comportamento silencioso por parte do público, manifestando-se apenas nas horas adequadas,.

Não era privilégio do público circense ser alvo das críticas e tentativas de enquadramento em um tipo idealizado de comportamento. Mas, por ser "puro entretenimento, diversão sem compromisso e sem caráter educativo", aquele espetáculo acabava por identificar e tipificar seu público como popular, sem nenhum compromisso com comportamentos civilizados, e associado a atitudes barulhentas, selvagens e deseducadas. Os versos de Arthur Azevedo passam a imagem de uma platéia de circo agitada e indômita, com reações próximas das de um público que assistia a uma comédia, isto é, ambos os públicos eram parecidos, ou os mesmos, e se divertiam muito. 
Uma característica marcante da teatralidade circense era a produção do espetáculo com o que de mais contemporâneo se vivenciava, explorando e incorporando o que havia de recente em termos artísticos e técnicos, como foi o caso do uso dos recursos da iluminação elétrica, numa espécie de "revolução" do espaço cênico do período. É o que se pode observar numa outra grande atração que foi anunciada, durante vários dias, sobre a apresentação da "incomparável” bailarina norte-americana Loïe Fuller, com sua famosa "dança serpentina" $(O$ Paiz, de 29.05 a 09.06.1894). Entretanto, não foi Loïe Fuller que estreou, mas sim Miss Emilie D'Armoy, noticiada como uma "discípula e imitadora incomparável" daquela artista. Anunciada a princípio para o dia 14 , a estréia só ocorreu em 19 de junho de 1894, porque o São Pedro passava por mais uma reforma:

(...) em conseqüência dos preparativos e montagem das luzes elétricas para a estréia da Serpentina (...) o maior sucesso do mundo inteiro; de pouco em pouco as luzes do gás se apagam, de súbito a dançarina entra em cena e os raios de luz elétrica a iluminam de verde, azul, amarelo e roxo, no seu amplo vestido, que se estende quando ela se agita, fazendo ondulações na Serpentina, vagas no açafate, azas na borboleta, etc. etc. (O Paiz, 14 e 19.06.1894).

Numa explosão total do espaço cênico à italiana, que pressupunha silêncio e toda atenção do público voltada exclusivamente para um palco fechado e capaz de fabricar ilusão e passividade, os circenses introduziram no teatro um picadeiro, um espaço aberto e circular que não escondia ou camuflava os instrumentos de trabalho. Além disso, todas as representações teatrais das pantomimas eram divididas entre o palco e o picadeiro, o que significava não ter nenhuma "parede teatral"; os atores eram vistos de todos os lados, ocupando todos os espaços cênicos.
Por isso, o que se quer observar é que não era improvável que Rozita de La Plata ou o conjunto que representava o espetáculo circense fizessem tanto sucesso quanto Sarah Bernhardt. As produções artísticas do período que utilizavam a dança, a ópera, o music-hall, a mímica, eram ao mesmo tempo marginalizadas e admiradas por uma "elite intelectual e letrada". Esse talvez fosse um dos dilemas que Arthur Azevedo e seus pares viviam naquele período. Ao definirem o que, para eles, significava o teatro e a arte, excluíam formas de representação e de ocupação dos espaços cênicos, que diferiam de determinados modelos imaginanados, qualquer que fosse sua qualidade. É provável que o problema se tornasse maior quando os lugares destinados para esse ou aquele tipo de espetáculo, definido a priori como sério e adequado, passavam a ser trocados e invadidos. Além de o Teatro São Pedro ser ocupado por um circo, Furtado Coelho se apresentava, naquele período, no Teatro Politeama Fluminense. Arthur escreveu a respeito, como Gravoche:
Incongruência.
No teatro o pulo do acrobata!
Vejo no circo a lágrima do drama!
No S. Pedro Rosita de La Plata!
Furtado Coelho no Politeama!... (O Paiz, 02.05.1894).

Se havia uma tentativa de distinguir, ou melhor, não misturar artes nem artistas, as experiências do dia-a-dia da cidade e das manifestaçôes culturais passavam ao largo dos desejos de demarcar o que seria a arte, o gosto do público, os temas, a função educativa e civilizadora do teatro. Os artistas que apresentavam formas diferenciadas de atuação, que não se encaixavam naquelas definições, como os circenses, desenvolviam diversas teatralidades, que, na sua diversidade e multiplicidade, atendiam ou mesmo produziam os gostos do público.

Em 1898, o mesmo Frank Brown voltou a ocupar o Teatro São Pedro de Alcântara. Mes- 
mo negando-se a assistir ao espetáculo e diferentemente de suas manifestações anteriores, Azevedo deixava que o público julgasse por si próprio:

No velho São Pedro, transformado de novo em circo de cavalinhos, está uma companhia eqüestre dirigida pelo popular Frank Brown e da qual faz parte a famosa Rosita de La Plata. Ainda lá não fui. Pelo que tenho ouvido, as opiniōes dividem-se: dizem uns que a companhia é muito boa e outros que não presta para nada. Não sei. O leitor vá ao São Pedro julgar por si (A Notícia, 30.06.1898).

Seis meses depois, em dezembro de 1899, um novo circo ocupou o São Pedro e, dessa vez, teve uma recepção um pouco diferente por parte dos cronistas teatrais. Tratava-se do Circo SulAmericano - sob direção de Anchyses Pery, filho de Manoel Pery -, já falecido, saudado pela imprensa como "finalmente" uma companhia "organizada quase exclusivamente com elementos nacionais, agradou mais e promete uma série de representações mais frutuosas que as últimas companhias estrangeiras que têm funcionado naquele teatro" (O Paiz, 04.12.1899).

A questão da "brasilidade" da família Pery, usada em contraposição às companhias, não necessariamente circenses, cujos diretores eram estrangeiros, iria permear o discurso de grande parte dos cronistas e memorialistas do século XX. Os circenses já utilizavam como chamariz de propaganda as famílias ou artistas brasileiros que faziam parte de seus quadros. Os principais destaques, em 1899, eram os palhaços Polydoro - que, apesar de sua origem portuguesa, circense desde 1870 no Brasil, é considerado, por uma parte dos memorialistas do circo, o "pai dos palhaços brasileiros" - e o "brasileiro Augusto Duarte", que juntos cantavam e dançavam chulas e lundus.

Mesmo anunciando em sua programação artistas de diversas origens, característica dos circos, o fato era que Anchyses Pery e seus irmãos eram brasileiros de nascimento. Parece que, por ser uma companhia formada "quase que exclusivamente" por nacionais, os cronistas não a criticaram, quando da sua estréia, e nem analisaram negativamente o fato de que de novo o teatro seria reformado. Ao contrário, falou-se do excelente espetáculo e do quanto agradou.

Na programação, o Circo Sul-Americano anunciava uma "catapulta de novidades" e números executados como os eqüestres, saltos e acrobacias. Nos intervalos, tocando no saguão do teatro, bandas de música do corpo de Infantaria da Marinha e do $1^{\circ}$ Batalhão de Infantaria do Exército, "gentilmente cedidas por seus dignos comandantes" (O Paiz, 10 a 31 de dezembro de 1899). Mesmo que toda essa programação fosse muito chamativa e atraente, as pantomimas ainda eram as atrações de maior peso.

Os Pery encenavam a maioria das pantomimas levadas nos circos. Uma em particular, a pantomima aquática, mexeu desta vez significativamente com a atenção da crônica e do público, como também provocou uma importante reforma em todo o palco do São Pedro, exigindo uma montagem e instalação de cenário e iluminação, além de uma produção mais elaborada dos figurinos e músicas, adequados para o desempenho da destreza física dos artistas.

Não era a primeira vez que o público do Rio de Janeiro assistia à montagem da pantomima aquática, mas era a primeira vez que era realizada no Teatro São Pedro de Alcântara. Explorando ao máximo o espaço cênico, sua trama e cenografia pressupunham movimentos de multidōes, efeitos de maquinaria, cenas feéricas, engenhosidades arquitetônicas (plataformas, pontes etc.), transformações instantâneas de cenário, e a incorporação abundante do que de mais recente pudesse ter sido inventado, como a utilização da luz elétrica (cf. Roubine, 1998, p. 121).

$\mathrm{Na}$ descrição da pantomima, temos: uma grande bacia de borracha colocada no picadeiro central, uma máquina a vapor, que, acionada, faria jorrar água em seis grandes calhas, na altu- 
ra das galerias e à vista do espectador, para encher a bacia. A quantidade de litros de água variava muito. Os Pery anunciavam que iriam colocar "80.000 litros de água na pista em 60 segundos", uma "verdadeira regata no S. Pedro". Cem pessoas de ambos os sexos tomariam parte na pantomima, com 20 números de música e mise en scène dos Irmãos Pery. Em pouco tempo o circo, ou seja, o Teatro São Pedro tornava-se uma grande lagoa por onde navegavam diversas canoas, botes, além de lavadeiras e pescadores, com figurinos a caráter. Havia um momento em que o lago ficava iluminado pela luz elétrica, assim como uma ponte que atravessava de um lado a outro do picadeiro, onde várias cenas se passavam: casamento, perseguição dos policiais, sua queda e a dos noivos na água, bailados, assim como o final apoteótico com fogos de artifícios no centro da ponte (O Paiz, 03.01.1892 e 22-23.12.1899).

A descrição dessa pantomima aquática pelos jornais foi o mais próximo que se consegue chegar do modelo do que seriam os primeiros filmes mudos e os temas de suas histórias. A crítica da coluna Artes e Artistas, no dia seguinte à estréia dessa pantomima, além dos elogios, fornece mais detalhes de sua montagem e do quanto a incorporação de tecnologia, inovadora para a época, atraía o público, incluindo os próprios cronistas:

Anteontem foi uma verdadeira maravilha a, aliás, conhecidíssima pantomima aquática, tal o efeito deslumbrante produzido pela quantidade de lâmpadas de variadas cores, que iluminaram a ponte colocada em toda a largura. Não menos contribuiu para o alto brilho de execução técnica o fogo de artifício e, sendo tudo uma deliciosa surpresa, os espectadores não prodigalizaram aplausos aos artistas e especialmente a Anchyses Pery, que não olhou o sacrifício para levar à cena a célebre pantomima (...) (O Paiz, 24.12.1899).

O gosto do público e a mistura de gêneros e artistas, contrariando de certa forma a idéia da "inteligência da platéia", justificariam o tom lamentoso de Arthur Azevedo comentando o fracasso de público de sua peça $O$ badejo, que estava sendo apresentada no Teatro Recreio Dramático, pedindo "instantaneamente ao público e à imprensa” que não o acusassem de arrastar a "clâmide sagrada da Arte na lama da opereta e da revista" como forma de sobrevivência (O Paiz, 06.12.1899).

É possível que Arthur estivesse se referindo ao fato de ser autor de peças de gêneros opereta e revista - que ele ao mesmo tempo em que condenava era "obrigado" a escrever se quisesse sobreviver, pois do chamado teatro sério não haveria como esperar alimentos para a sua família. Alguns dias depois que ele escreveu aquele apelo, no dia 25 de dezembro de 1900, dois eventos parece que conspiraram a favor para que ele se visse forçado a arrastar o manto sagrado da arte com "a" maiúsculo, na lama. A coincidência da inauguração do Café-Concerto Moulin Rouge (antigo Teatro Variedades), de Paschoal Segreto (com artistas de fama "vindos diretamente da Europa", entre estes muitos circenses, e a própria família Pery na inauguração), com a apresentação, no Teatro Apollo, da festa artística da atriz Lucinda Simões, oferecida aos "homens de letras do Brasil". Entretanto, o segundo evento foi um enorme fracasso de público. E o pior, para Azevedo foi que

Os próprios homens de letras a quem a beneficiada oferecera a sua festa corresponderam a essa delicadeza não indo lá. Éramos seis...oito, se tanto! (...) Apontei meia dúzia de motivos, cada qual mais forte, para que no Apollo houvesse uma enchente monumental; agora vou apontar um único, porém mais forte que todos aqueles seis reunidos, para justificar a vazante: inaugurava-se o Moulin Rouge, e entre o café-cantante e o teatro, o público prefere aquele (O Paiz, 24.12.1900).

O que se observa, mais uma vez, é que o público que freqüentava os teatros, os cafés-concertos e os circos era socialmente heterogêneo e 
tinha acesso, como consumidor, a todas as formas de produções artísticas ofertadas. No caso dos circenses, em particular, a situação se diferenciava pois eles iam a cidades, vilas e lugarejos a que o teatro não chegava. Enquanto não se construía o Teatro Municipal, e na impossibilidade de a maioria dos brasileiros ir ao Rio de Janeiro, vários grupos de artistas, principalmente os circenses, iam cumprindo o papel de produzir e divulgar expressōes culturais que resultavam em teatralidades envolvendo gêneros e ritmos distintos, artistas nacionais e estrangeiros, e formas heterogêneas de se organizar e se produzir espetáculos.

\section{Arthur Azevedo e Benjamin de Oliveira}

Em 1906, o Circo Spinelli, que tinha como principal atração Benjamim de Oliveira, estava armado no boulevard de São Cristóvão, mesmo bairro em que morava Arthur Azevedo. Nos anos anteriores o autor tinha se tornado amigo pessoal de Benjamim, e encaminhado, inclusive, diversos atores e atrizes teatrais, além de cantores de teatro para se empregarem naquele circo. Em 23 de fevereiro de 1907, Azevedo escreveria uma crônica com muitos elogios ao espetáculo protagonizado por Oliveira. Chamava a atenção do leitor, particularmente, à representação teatral das adaptações produzidas pelo artista. Benjamim de Oliveira era ator, autor, músico, instrumentista, dançarino, palhaço, acrobata, e foi um dos primeiros a gravar discos e a participar de filmes no Brasil. Por isso Arthur de Azevedo comparava-o a Tabarin. Entretanto, no mesmo período em que escrevia favoravelmente a Benjamim de Oliveira, Arthur Azevedo não deixou de expressar as relações tensas que mantinha com as companhias circenses que "invadiam" os "templos do teatro nacional".

(...) anuncia-se que mais uma vez, e não será com certeza a última, o glorioso e venerado teatro S. Pedro de Alcântara será transformado em circo de cavalinhos. Quando as mais poderosas razóes tivéssemos para supor que entramos definitivamente numa época de transformação moral, bastava, para nos convencer do contrário, a inconsciência feroz com que se insulta assim o teatro digno, pela tradição, de ser considerado um monumento histórico, intimamente ligado à fundação de nossa nacionalidade. Não falo do seu passado artístico, porque no Rio de Janeiro a arte, ao que parece, é uma recomendação negativa.

Por isso, bem-vinda seja a "Caravana", essa nova associação fundada por iniciativa de Coelho Netto, que vem, na realidade, ensinar a nossa gente a respeitar o espólio sagrado dos nossos avós, e fazer com que ela se envergonhe de mostrar a $\mathrm{D}$. Carlos $\mathrm{I}$, não artistas, mas cachorros, cavalos e macacos, no teatro construído por D. João VI. É preciso notar que, para fazer a fortuna de uma companhia eqüestre, um teatro não vale um circo. A prova aí está no popular Spinelli que já deu duzentos e tantos espetáculos consecutivos, e o seu circo ainda se enche todas as noites, e é a alegria do nosso bairro mais populoso. Vá o Spinelli para S. Pedro, e verá como tudo lhe corre torto (O Paiz, 12.08.1907, coluna "Palestra"; grifo meu).

Eram Frank Brown e Rozita que de novo estreavam no São Pedro. Mas, além de animais e acrobacias, havia aumentado o número de artistas "nacionais", inclusive alguns que naquela temporada ora estavam no Spinelli ora com Brown. Acrescente-se a isto o fato de que estes artistas ampliaram as representações teatrais com pantomimas.

Essa crônica sintetizava a posição de Arthur Azevedo em relação ao circo. Para ele, mesmo manifestando seu apreço pelos espetáculos circenses que se apresentavam no Spinelli, teatro e circo eram atividades artísticas que não deveriam se misturar, ou melhor, cada uma deveria ocupar o seu espaço próprio. Afinal, a formação de "nossa nacionalidade" só poderia ocorrer a partir do teatro. 


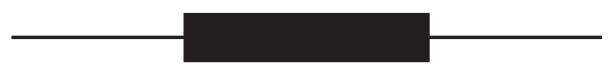

\section{Referências bilbiográficas}

ABREU, M. O império do Divino: festas religiosas e cultura popular no Rio de Janeiro, 1830-1900. Rio de Janeiro/São Paulo: Nova Fronteira/Fapesp, 1999.

ARAÚJO, V. de P. A bela época do cinema brasileiro. São Paulo: Editora Perspectiva, 1976.

CASTAGNINO, R. H. El circo criollo - Datos y documentos para su historia 1757-1924. Buenos Aires: Plus Ultra, 1969.

COARACY, V. Memórias da cidade do Rio de Janeiro. Rio de Janeiro: José Olympio Editora, 1965, V. 3.

COELHO, F. \& SERRA, J. O remorso vivo. Música de Arthur Napoleão. 2a ed. São Paulo: Livraria de C. Teixeira, Biblioteca Dramática Popular, n. 58, s/d.

DAMASCENO, A. Palco, salão e picadeiro em Porto Alegre no século XIX (contribuiçôes para o estudo do processo cultural do Rio Grande do Sul). Rio de Janeiro: Editora Globo, 1956.

DUARTE, R. H. Noites circenses - Espetáculos de circo e teatro em Minas Gerais no século XIX. Campinas: Editora da Unicamp, 1995.

EDMUNDO, L. O Rio de Janeiro do meu Tempo. Rio de Janeiro: Imprensa Nacional, 1938.

FARIA, J. R. O teatro realista no Brasil: 1855:1865. São Paulo: Perspectiva/EDSUP, 1993.

HAUSER, A. História social da arte e da literatura. São Paulo: Martins Fontes, 1998.

LIMA, E. F. W. Arquitetura do espetáculo: teatros e cinemas na formação da Praça Tiradentes e da Cinelância. Rio de Janeiro: Editora da UFRJ, 2000.

MENCARELLI, F. A. Cena aberta: a absolvição de um bilontra e o teatro de revista de Arthur Azevedo. Campinas: Editora da Unicamp/Centro de Pesquisa em História Social da Cultura, 1999.

Revista da Casa dos Artistas. Vigésimo Aniversário da Casa dos Artistas - Artistas do passado - Traços biográficos - Furtado Coelho (Luiz Candido Furtado Coelho), 24.08.1938.

ROUBINE, J-J. A linguagem da encenação teatral. Rio de Janeiro: Jorge Zahar, 1998.

RUIZ, R. Teatro de revista no Brasil: do início à I Guerra Mundial. Rio de Janeiro: Inacen, 1988.

SEIBEL, B. História del circo. Buenos Aires: Ediciones del Sol, 1993.

SOUZA, S. C. M. de. As noites do Ginásio. Teatro e tensôes culturais na Corte (1832-1868). Campinas: Editora da Unicamp/Cecult, 2002.

SÜSSEKIND, F. “Crítica a vapor. Notas sobre a crónica teatral brasileira da virada de século”, IN CANDIDO, A. et. al. A crônica: o gênero, sua fixaçāo e suas transformaçôes no Brasil. Campinas/ Rio de Janeiro: Editora da Unicamp/Fundação Casa de Rui Barbosa, 1992, p. 355-404.

THÉTARD, H. La merveilleuse histoire du cirque. Paris: Prisma, 1947. 